\title{
Expression and prognostic significance of doublecortin-like kinase 1 in patients with hepatocellular carcinoma
}

\author{
MENGJIAO FAN*, NIANSONG QIAN* ${ }^{*}$ and GUANGHAI DAI \\ Department of Oncology, Chinese People's Liberation Army General Hospital, Beijing 100853, P.R. China
}

Received July 4, 2016; Accepted July 20, 2017

DOI: $10.3892 / 01.2017 .7082$

\begin{abstract}
Doublecortin-like kinase 1 (DCLK1), a putative cancer stem cell marker in intestinal and pancreatic tumors, is associated with tumor pathogenesis and progression, and poor survival outcomes in numerous types of cancer. However, DCLK1 expression and its prognostic value remain unclear in hepatocellular carcinoma (HCC). In the present study, the expression of DCLK1 was assessed using immunohistochemistry in 96 resected HCC and 68 adjacent tissue specimens. The staining intensity and the percentage of stained cells were scored on a scale of $0-3$ and $0-4$, respectively. Tissue was defined as positive for DCLK1 if the composite multiple score was >3. Cytoplasmic expression of DCLK1 was observed in HCC and adjacent tissue specimens with an expression rate of $81 \%$ (78/96) and 74\% (50/68), respectively; the median score was 4.6 and 3.9, respectively, and no statistically significant difference was observed between HCC and adjacent tissues ( $\mathrm{P}=0.087)$. DCLK1 expression was positively associated with intrahepatic metastasis $(\mathrm{P}=0.035)$. Furthermore, univariate analysis revealed that DCLK1 expression was significantly associated with poor disease-free survival (DFS) and overall survival $(\mathrm{P}=0.024$ and 0.034$)$. Multivariate analysis also demonstrated that DCLK1 expression was an independent prognostic factor for DFS in $\mathrm{HCC}(\mathrm{P}=0.019$; hazard ratio, 1.546; $95 \%$ confidence interval, 1.330-1.725). Stratified Kaplan-Meier survival curves revealed that DCLK1 expression predicted poorer DFS with respect to positivity for three characteristics: Portal venous metastasis, intrahepatic metastasis, and cirrhosis $(\mathrm{P}=0.020$,
\end{abstract}

Correspondence to: Dr Guanghai Dai, Department of Oncology, Chinese People's Liberation Army General Hospital, 28 Fuxing Road, Beijing 100853, P.R. China

E-mail: daigh60@sohu.com

*Contributed equally

Abbreviations: DCLK1, doublecortin-like kinase 1; HCC, hepatocellular carcinoma; CSC, cancer stem cell; IHC, immunohistochemistry; DFS, disease-free survival; OS, overall survival; EMT, epithelial-mesenchymal transition

Key words: doublecortin-like kinase 1, immunohistochemistry, hepatocellular carcinoma, prognosis
$\mathrm{P}=0.007$ and $\mathrm{P}=0.017$, respectively). Collectively, the results of the present study suggested that DCLK1, functioning as a tumor promoter, is frequently overexpressed in $\mathrm{HCC}$, and that DCLK1 expression is associated with poor DFS in patients with HCC. DCLK1 may represent a promising therapeutic target in $\mathrm{HCC}$ and requires further study.

\section{Introduction}

According to the global cancer statistics in 2012, hepatocellular carcinoma (HCC) is the sixth most common cancer globally, and the survival outcomes are poor with 5-year overall survival (OS) rates estimated at $<12 \%(1,2)$. Surgery or transplantation remain the mainstays of curative therapy for early disease. Ablative strategies can also cure tumors. However, relatively few patients are eligible for curative therapy due to the late appearance of symptoms (3). Medical strategies for treating HCC have advanced little during the past 20 years. Traditional systemic chemotherapy represents a limited treatment option associated with a small survival advantage (4). Therefore, identifying novel molecular biomarkers with the potential to evaluate tumor recurrence and progression is crucial.

The doublecortin-like kinase 1 (DCLK1) gene, located at human chromosome 13q13.3, encodes a member of the protein kinase superfamily and the doublecortin family (5). The kinase encoded by this gene was first described in the context of the nervous system, in which DCLK1 catalyzed the polymerization of tubulin into microtubules (6). Giannakis et al (7) were the first to demonstrate that DCLK1 regulated biological processes outside of the central nervous system. This discovery revealed that DCLK1 was associated with tumorigenesis and its progression. Immunohistochemical analysis using a DCLK1 antibody revealed single cell staining in intestinal crypt sections and gastric isthmus cells, which suggested that DCLK1 represented a marker of adult gastric and small intestinal stem cells (8). Nakanishi et al (9) subsequently demonstrated that DCLK1 marked cancer stem cells (CSCs) rather than normal stem cells in the polyps of APC multiple intestinal neoplasia $(\mathrm{Min}) /+$ mice using lineage-tracing experiments. In addition, DCLK1 was reported to be a putative CSC marker in pancreatic and colon cancer via the same strategy $(10,11)$.

CSCs were first identified in acute myeloid leukemia (12) and subsequently revealed in breast (13) and pancreatic (14) tumors, and in HCC (15). Accounting for 1-2\% of total tumor 
cells, CSCs exhibited similar characteristics to those of normal stem cells, including self-renewal and unlimited proliferation and differentiation (16), and contributed to cancer progression, metastasis and therapeutic resistance (17). CSCs may generate more differentiated and rapidly proliferating cells, and thereby form the majority of the tumor $(18,19)$.

Despite the CSC marker hypothesis, multiple studies demonstrated that DCLK1 negatively regulated tumor suppressor microRNAs (miRNAs/miRs) associated with tumor initiation, progression and metastasis (20-24). Furthermore, previous studies have demonstrated DCLK1 expression in multiple types of solid tumor, including colon, intestinal and pancreatic cancer, and HCC (20,25-27). In addition, it has been revealed that patients with a high (>4) DCLK1 staining score are associated with increased cancer-specific mortality rates compared with those with a low (0-4) DCLK1 staining score in colorectal neoplasia (27). To the best of our knowledge, no study has been performed to assess the association between DCLK1 expression and survival outcome in patients with HCC. Therefore, the present study evaluated DCLK1 expression in HCC using immunohistochemical analysis and assessed its association with clinicopathological features and survival outcome.

\section{Materials and methods}

Patients and tissue samples. A total of 96 HCC and 68 adjacent tissue samples from patients with HCC who had not undergone chemotherapy, targeted therapy, radiotherapy or immunotherapy were obtained from the Department of Pathology of the Chinese People's Liberation Army General Hospital (Beijing, China) between August 2011 and August 2012. Clinicopathological features of the patients are provided in Table I. To analyze outcome data, the date of surgery was defined as the beginning of disease-free survival (DFS; time to disease progression) and overall survival (OS; time to mortality). Follow-up ceased in November 2015 and the median follow-up time was 30 months. The protocol of the present study was approved by the Chinese Ministry of Health and the Ethics Committee of the Chinese People's Liberation Army General Hospital in accordance with the ethical principles of the Declaration of Helsinki. Prior to the present study, all patients provided written informed consent to participate.

Immunohistochemistry (IHC). IHC analysis was conducted using Image-Pro Plus 6.0 offered by Media Cybernetics, Inc. (Rockville, MD, USA). DCLK1 expression in the 96 HCC and 68 adjacent tissue samples from patients with HCC was assessed using IHC and the procedures were the same (28). Subsequent to fixing with $10 \%$ neutral formaldehyde at room temperature for $20 \mathrm{~min}$ (cat. no. ZI-4002; OriGene Technologies, Inc., Rockville, MD, USA) and paraffin embedding, the tissues were cut to prepare $4-\mu \mathrm{m}$ sections that were mounted on silane-coated glass slides. In the present study, rabbit monoclonal anti-DCLK1 (dilution, 1:700; cat. no., ab109029; Abcam, Cambridge, MA, USA) was the primary antibody. Following deparaffinization in xylene solution and rehydration via a reduced alcohol series (concentration 100, 95, 80 and $70 \%$ ), slides underwent epitope retrieval in $0.01 \mathrm{~mol} / \mathrm{l}$
Table I. Descriptive statistics for patients with hepatocellular carcinoma.

\begin{tabular}{|c|c|}
\hline Characteristic & Value \\
\hline Age, years & $51.7 \pm 9.5^{\mathrm{a}}$ \\
\hline Tumor size, $\mathrm{cm}$ & $4.6 \pm 3.4^{\mathrm{a}}$ \\
\hline \multicolumn{2}{|l|}{$\operatorname{Sex}, \mathrm{n}(\%)$} \\
\hline Male & $78(81)$ \\
\hline Female & $18(19)$ \\
\hline \multicolumn{2}{|l|}{ Grade, n (\%) } \\
\hline Well-differentiated & $38(40)$ \\
\hline Moderately differentiated & $33(34)$ \\
\hline Poorly differentiated & $25(26)$ \\
\hline \multicolumn{2}{|c|}{ Portal venous metastasis, n (\%) } \\
\hline Negative & $54(56)$ \\
\hline Positive & $42(44)$ \\
\hline \multicolumn{2}{|c|}{ Hepatic venous metastasis, n (\%) } \\
\hline Negative & $72(75)$ \\
\hline Positive & $24(25)$ \\
\hline \multicolumn{2}{|l|}{ Bile duct invasion, $\mathrm{n}(\%)$} \\
\hline Negative & $92(96)$ \\
\hline Positive & $4(4)$ \\
\hline \multicolumn{2}{|l|}{ Intrahepatic metastasis, n (\%) } \\
\hline Negative & $46(48)$ \\
\hline Positive & $50(52)$ \\
\hline \multicolumn{2}{|l|}{ Cirrhosis, n (\%) } \\
\hline No & $43(45)$ \\
\hline Yes & $53(55)$ \\
\hline \multicolumn{2}{|l|}{ Hepatitis B virus, n (\%) } \\
\hline Negative & $85(89)$ \\
\hline Positive & $11(11)$ \\
\hline \multicolumn{2}{|l|}{ Recurrence, n (\%) } \\
\hline No & $46(48)$ \\
\hline Yes & $50(52)$ \\
\hline \multicolumn{2}{|l|}{ Mortality induced, n (\%) } \\
\hline No & $63(66)$ \\
\hline Yes & $33(34)$ \\
\hline \multicolumn{2}{|l|}{ Tumor size, n (\%) } \\
\hline$<5 \mathrm{~cm}$ & $75(78)$ \\
\hline$>5 \mathrm{~cm}$ & $21(22)$ \\
\hline \multicolumn{2}{|l|}{ DCLK1 expression, n (\%) } \\
\hline No & $18(19)$ \\
\hline Yes & $78(81)$ \\
\hline
\end{tabular}

${ }^{a}$ Mean \pm standard deviation. DCLK11, doublecortin-like kinase 1.

citrate buffer $\left(\mathrm{pH} \mathrm{6.0)}\right.$ at $120^{\circ} \mathrm{C}$ for 4 min using a pressure cooker. Subsequently, endogenous peroxidase activity was blocked using 3\% hydrogen peroxide at room temperature for 30 min. Goat serum (10\%; BioSharp, Hefei, China) was then used to block non-specific binding sites at room temperature for $30 \mathrm{~min}$. Sections were subsequently incubated with the 
A

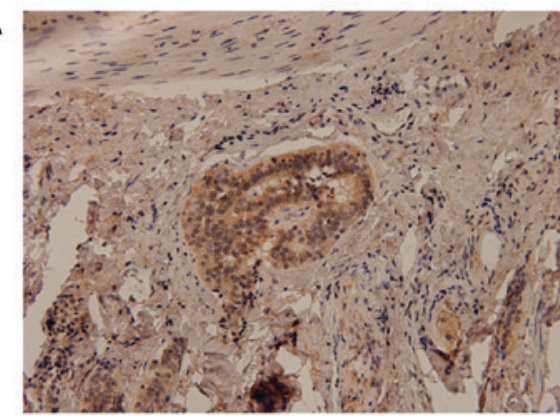

C

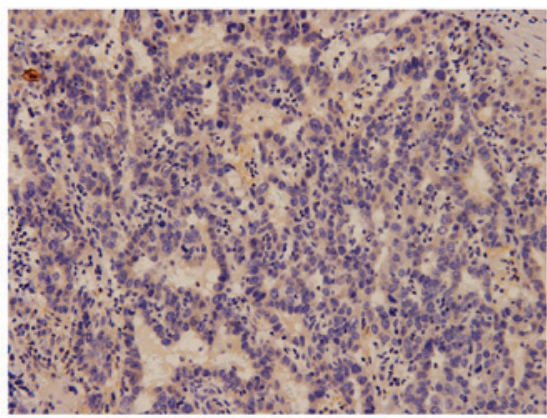

B
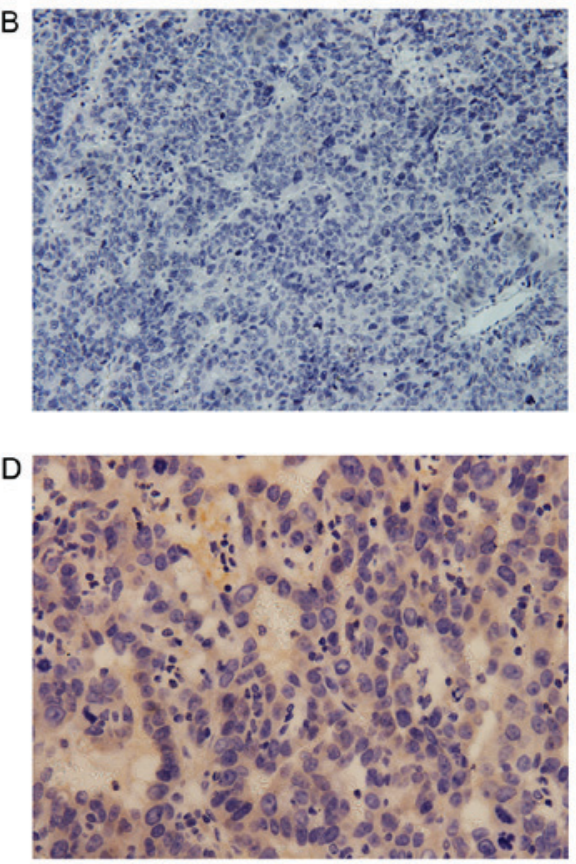

Figure 1. Representative immunohistochemical staining of DCLK1. Immunohistochemical staining of (A) the positive control (magnification, x200) and (B) the negative control (magnification, x200). The expression and cytoplasmic distribution of immunoreactive DCLK1 in hepatocellular carcinoma tissue specimens at magnification (C) x200 and (D) x400. DCLK1, doublecortin-like kinase 1.

anti-DCLK1 antibody (1:700, diluted using PBS) overnight at $4^{\circ} \mathrm{C}$. Subsequent to washing with PBS and distilled water, the sections were incubated with anti-rabbit secondary antibody (dilution, 1:100; cat. no. PV-6001; OriGene Technologies, Inc.) at $37^{\circ} \mathrm{C}$ for $30 \mathrm{~min}$. Sections were then treated with 3,3'-diaminobenzidine (dilution, 1:20; cat. no. ZLI-9017; OriGene Technologies, Inc.) to visualize antibody reactions and counterstained for $\sim 4 \mathrm{~min}$ at room temperature with Mayer's hematoxylin to develop cell nuclei. Subsequently, sections were dehydrated in an ascending alcohol series (70, 80, 95 and $100 \%$ ) and mounted using neutral balsam (cat. no. GB590; Beijing Solarbio Science \& Technology Co., Ltd., Beijing, China). The negative control experiment was performed according to the same IHC procedure, except the anti-DCLK1 antibody (dilution, 1:500; cat. no., EPR6085; Epitomics; Abcam), and the same IHC procedure was performed on the positive control, which was human rectal neuroendocrine tumor tissues from the Department of Pathology of the Chinese People's Liberation Army General Hospital (Beijing, China; Fig. 1) (29).

IHC scoring. The results of DCLK1 IHC staining were analyzed by two independent pathologists (the staff of the Chinese People's Liberation Army General Hospital Pathology Department) blinded to the other markers and the nature of the samples. In total, 5 microscopic fields were randomly selected for each slide. A microscope (BX-53; Olympus Corporation; Japan; magnification, x400) was used to observe the staining of the target protein on the tissues. The staining scoring was assessed for two parameters: i) The percentage of stained cells and ii) staining intensity (30). A score of 0, 1, 2 and 3 for non-reactive, weak, moderate and strong, respectively, was used to evaluate the staining intensity. Similarly, the percentage of stained cells was scored as $0(0 \%), 1(<10 \%)$,
2 (10-40\%), 3 (41-60\%) and 4 (>60\%). The DCLK1 staining score was the product of the two scores. The expression of DCLK1 was defined as positive when the composite score was $>3$ and as negative when the composite score was 0-2 (31).

Statistical analysis. Data are presented as the mean \pm standard deviation, or as frequency. IBM SPSS Statistics 22 (IBM Corp., Armonk, NY, USA) was used for statistical analysis. The association between different HCC pathologies and DCLK1 expression was evaluated using the $\chi^{2}$ test or Fisher's exact test. DFS and OS curves were estimated using the Kaplan-Meier method and the log-rank test. Multivariate analysis was assessed using the Cox proportional hazards model. $\mathrm{P}<0.05$ was considered to indicate a statistically significant difference.

\section{Results}

DCLK1 is expressed in HCC and adjacent tissues. In the present study, the expression of DCLK1 was analyzed using IHC performed on 96 resected HCC and 68 adjacent tissue specimens. Cytoplasmic expression of DCLK1 was observed in HCC (Fig. 1) and adjacent tissue specimens (Fig. 2); the positive expression rate was $81 \%(78 / 96)$ and $74 \%(50 / 68)$, respectively, while the median score was 4.6 and 3.9, respectively, with no statistically significant difference observed between the HCC and adjacent tissues $(\mathrm{P}=0.087)$.

Association between DCLK1 expression and pathological parameters. The present study assessed the overall clinical characteristics of 96 patients with HCC and their association with the DCLK1 staining results. DCLK1 expression was positively associated with intrahepatic metastasis $(\mathrm{P}=0.035)$, while no association was identified with the other clinical 
Table II. Association between DCLK1 expression and pathological parameters in patients with hepatocellular carcinoma.

DCLK1 expression

\begin{tabular}{|c|c|c|c|c|}
\hline & & & & \\
\hline Characteristic & Total, $\mathrm{n}$ & Negative, $\mathrm{n}$ & Positive, $\mathrm{n}$ & P-value ${ }^{a}$ \\
\hline Tumor size, $\mathrm{cm}$ & & & & 0.755 \\
\hline$<5$ & 75 & 15 & 60 & \\
\hline$>5$ & 21 & 3 & 18 & \\
\hline Grade & & & & 0.189 \\
\hline Well-differentiated & 38 & 10 & 28 & \\
\hline Moderately differentiated & 33 & 6 & 27 & \\
\hline Poorly differentiated & 25 & 2 & 23 & \\
\hline Portal venous metastasis & & & & 0.605 \\
\hline Negative & 54 & 9 & 45 & \\
\hline Positive & 42 & 9 & 33 & \\
\hline Hepatic venous metastasis & & & & 0.763 \\
\hline Negative & 72 & 14 & 58 & \\
\hline Positive & 24 & 4 & 20 & \\
\hline Bile duct invasion & & & & 0.571 \\
\hline Negative & 92 & 17 & 75 & \\
\hline Positive & 4 & 1 & 3 & \\
\hline Intrahepatic metastasis & & & & 0.035 \\
\hline Negative & 46 & 14 & 38 & \\
\hline Positive & 50 & 4 & 46 & \\
\hline Cirrhosis & & & & 0.974 \\
\hline No & 43 & 8 & 35 & \\
\hline Yes & 53 & 10 & 43 & \\
\hline Hepatitis B virus & & & & 0.427 \\
\hline Negative & 85 & 15 & 70 & \\
\hline Positive & 11 & 3 & 8 & \\
\hline Recurrence & & & & 0.844 \\
\hline No & 46 & 9 & 37 & \\
\hline Yes & 50 & 9 & 41 & \\
\hline Sex & & & & 0.739 \\
\hline Male & 78 & 14 & 64 & \\
\hline Female & 18 & 4 & 14 & \\
\hline
\end{tabular}

${ }^{a} \chi^{2}$ test. DCLK1, doublecortin-like kinase 1.
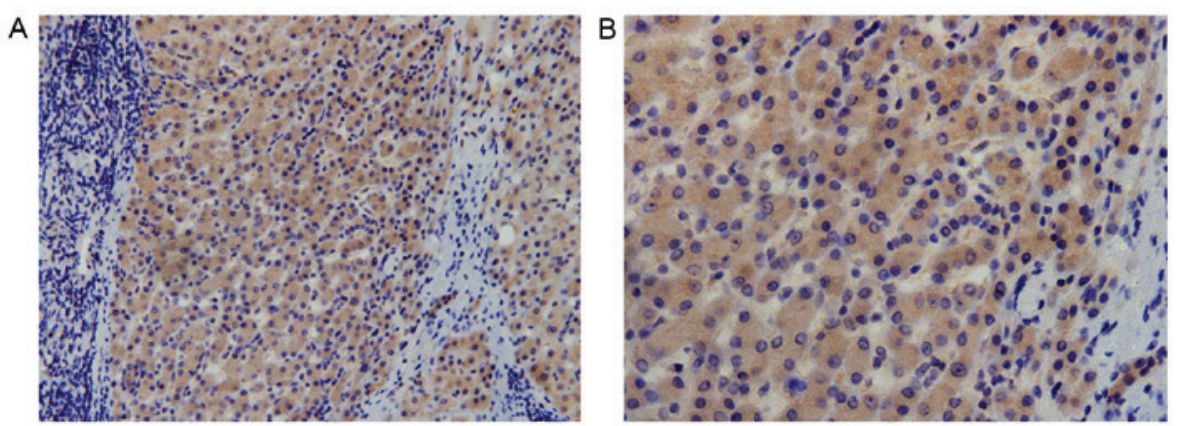

Figure 2. Expression of DCLK1 in hepatocellular carcinoma-adjacent tissue specimens. The expression and cytoplasmic distribution of immunoreactive DCLK1 at magnification (A) x200 and (B) x400. DCLK1, doublecortin-like kinase 1.

predictor variables, including sex, grade, hepatic venous metastasis, portal venous metastasis, bile duct invasion and cirrhosis status $(\mathrm{P}=0.739, \mathrm{P}=0.189, \mathrm{P}=0.763, \mathrm{P}=0.605, \mathrm{P}=0.571$ and $\mathrm{P}=0.974$, respectively) (Table II). 
Table III. Univariate analysis.

\begin{tabular}{lr}
\hline Characteristic & P-value \\
\hline DFS & \\
Tumor size (<5 vs. $>5 \mathrm{~cm}$ ) & $<0.001$ \\
Grade (1 vs. 2 vs. 3) & 0.008 \\
Portal venous metastasis (negative vs. positive) & $<0.001$ \\
Hepatic venous metastasis (negative vs. positive) & 0.004 \\
Bile duct invasion (negative vs. positive) & 0.245 \\
Intrahepatic metastasis (negative vs. positive) & $<0.001$ \\
Cirrhosis (no vs. yes) & $<0.001$ \\
Hepatitis B virus (negative vs. positive) & 0.176 \\
DCLK1 (negative vs. positive) & 0.024 \\
OS & $<0.001$ \\
Tumor size (<5 vs. $>5$ cm) & 0.141 \\
Grade (1 vs. 2 vs. 3) & 0.002 \\
Portal venous metastasis (negative vs. positive) & 0.004 \\
Hepatic venous metastasis (negative vs. positive) & 0.270 \\
Bile duct invasion (negative vs. positive) & $<0.001$ \\
Intrahepatic metastasis (negative vs. positive) & $<0.001$ \\
Cirrhosis (no vs. yes) & 0.277 \\
Hepatitis B virus (negative vs. positive) & 0.013 \\
Recurrence (no vs. yes) & 0.034 \\
DCLK1 (negative vs. positive) & \\
\hline
\end{tabular}

${ }^{a}$ Log-rank test. DFS, disease-free survival; DCLK1, doublecortin-like kinase 1; OS, overall survival.

Prognostic value of DCLK1 expression. The median follow-up time was 30 months. Compared with DCLK1 negative expression, the survival rate in the positive expression were significantly reduced (both $\mathrm{P}<0.00$; Fig. 3 ). Table III provides the univariate analysis and the potential prognostic factors. DCLK1 expression, tumor size $(>5 \mathrm{~cm})$, portal venous metastasis, intrahepatic metastasis, hepatic venous metastasis, grade and cirrhosis were associated with poor DFS $(\mathrm{P}=0.024, \mathrm{P}<0.001, \mathrm{P}<0.001, \mathrm{P}<0.001, \mathrm{P}=0.004, \mathrm{P}=0.008$ and $\mathrm{P}<0.001$, respectively). No significant association was identified between DFS and bile duct invasion, or hepatitis B virus (Table III). Cox regression models were then constructed, which contained the factors of DCLK1 expression, in order to realize the role of DCLK1 expression in prognostic prediction. The results revealed that DCLK1 expression was an independent prognostic parameter for the DFS of patients with HCC $(\mathrm{P}=0.019$; Table IV), with an adjusted hazard ratio of 1.546 (95\% confidence interval, 1.330-1.725). A significant association was also demonstrated between DFS and portal venous metastasis, cirrhosis, hepatic venous metastasis and tumor size ( $>5 \mathrm{~cm} ; \mathrm{P}=0.021, \mathrm{P}=0.011, \mathrm{P}=0027$ and $\mathrm{P}<0.001$, respectively).

The present study also assessed the association between DCLK1 expression and OS. Kaplan-Meier analysis demonstrated that patients with DCLK1 expression were associated with decreased OS compared with those without $(\mathrm{P}=0.034)$. The significant impact of tumor size $(>5 \mathrm{~cm})$, portal venous metastasis, intrahepatic metastasis, hepatic venous metastasis, recurrence and cirrhosis on OS was also validated $(\mathrm{P}<0.001, \mathrm{P}=0.002, \mathrm{P}<0.001, \mathrm{P}=0.004, \mathrm{P}=0.013$ and $\mathrm{P}<0.001$, respectively) (Table III). Cox regression analysis using the aforementioned potential prognostic factors did not demonstrate a significant association between DCLK1 expression and OS $(\mathrm{P}=0.089)$, but showed the strong negative influence of tumor size $(>5 \mathrm{~cm})$, hepatic venous metastasis and cirrhosis on OS $(\mathrm{P}=0.018, \mathrm{P}=0.002$ and $\mathrm{P}=0.040$, respectively).

The present study revealed that DCLK1 expression in patients with $\mathrm{HCC}$ was an important independent prognostic factor of DFS that was not associated with portal venous metastasis, cirrhosis, hepatic venous metastasis or tumor size. However, DCLK1 expression was not demonstrated to be an independent predictor of OS in patients with HCC.

Status of DCLK1 expression in portal venous metastasis, intrahepatic metastasis and cirrhosis patient subgroups. Previous studies have suggested that portal venous metastasis, intrahepatic metastasis and cirrhosis may represent critical predictors of disease recurrence, metastasis and poor clinical outcome in patients with HCC (32-34). Therefore, the present study conducted further subgroup survival analysis stratified by portal venous metastasis, intrahepatic metastasis and cirrhosis status. Kaplan-Meier survival curves (Fig. 3) revealed that DCLK1 expression predicted poorer DFS in the patient subgroups positive for portal venous metastasis, intrahepatic metastasis, and cirrhosis $(\mathrm{P}=0.020,0.007$, and 0.017 , respectively) compared with their respective negative groups, which would provide evidence supporting the use of early interventions with more aggressive therapies following surgery in patients with HCC.

\section{Discussion}

In the present study, DCLK1 expression was analyzed using IHC performed on 96 resected HCC and 68 adjacent tissue specimens. DCLK1 expression was revealed in $81 \%(78 / 96)$ of the HCC specimens, which was consistent with the $83 \%$ (19/23) result of a previous study (31). Furthermore, the clinical significance of DCLK1 expression and its association with patient outcome were evaluated in 96 patients with HCC. The present study identified a positive association between DCLK1 expression and tumor intrahepatic metastasis, while no association was observed between DCLK1 expression and sex, grade, hepatic venous metastasis, portal venous metastasis, bile duct invasion or cirrhosis. Previous studies demonstrated that DCLK1 expression was associated with $\mathrm{T}$ stage and lymphatic vessel involvement in colorectal cancer (35). Although DCLK1 expression has been studied in $\mathrm{HCC}$, there is little data on the expression and survival significance of DCLK1 in patients with HCC. A previous study revealed that increased expression (staining score $>3$ ) of DCLK1 was associated with a decreased 5-year OS rate compared with decreased expression (staining score $<3$ ) in patients with gastric cancer (36). Consistent with this previous study, the present study demonstrated that DCLK1 expression was an independent prognostic factor of DFS in patients with HCC. To the best of our knowledge, the present study revealed for the first time that DCLK1 expression predicts poor DFS time in patients with $\mathrm{HCC}$ with portal venous metastasis, 
Table IV. Cox regression analysis of factors that could affect DFS and OS in patients with hepatocellular carcinoma.

\begin{tabular}{|c|c|c|c|}
\hline Factor & Hazard ratio & $95 \% \mathrm{CI}$ & P-value ${ }^{a}$ \\
\hline \multicolumn{4}{|l|}{ DFS } \\
\hline Tumor size, $\mathrm{cm}$ & 1.757 & $1.461-2.409$ & $<0.001$ \\
\hline \multicolumn{4}{|l|}{ Grade } \\
\hline Well-differentiated & 1.245 & $0.768-3.546$ & 0.578 \\
\hline Moderately differentiated & 1.831 & $0.598-5.602$ & 0.298 \\
\hline Poorly differentiated & 0.875 & $0.322-2.375$ & 0.793 \\
\hline Portal venous metastasis & 1.380 & $1.168-1.857$ & 0.021 \\
\hline Hepatic venous metastasis & 0.989 & $0.669-1.097$ & 0.027 \\
\hline Intrahepatic metastasis & 0.540 & $0.492-0.739$ & 0.080 \\
\hline Cirrhosis & 1.122 & $1.024-1.615$ & 0.011 \\
\hline DCLK1 & 1.546 & $1.330-1.725$ & 0.019 \\
\hline \multicolumn{4}{|l|}{ OS } \\
\hline Tumor size, $\mathrm{cm}$ & 1.401 & $1.188-1.856$ & 0.018 \\
\hline Portal venous metastasis & 0.633 & $0.296-1.355$ & 0.239 \\
\hline Hepatic venous metastasis & 2.300 & $2.139-2.651$ & 0.002 \\
\hline Intrahepatic metastasis & 0.533 & $0.178-1.580$ & 0.255 \\
\hline Cirrhosis & 0.607 & $0.346-0.731$ & 0.040 \\
\hline DCLK1 & 0.278 & $0.062-1.215$ & 0.089 \\
\hline Recurrence & 1.260 & $0.562-2.861$ & 0.575 \\
\hline
\end{tabular}

${ }^{a}$ Cox regression test. DFS, disease-free survival; OS, overall survival; CI, confidence interval; DCLK1, doublecortin-like kinase 1.

intrahepatic metastasis or cirrhosis. Collectively, these results suggested that DCLK1 expression may represent a novel potential prognostic biomarker for patients with HCC.

Since these results suggested that DCLK1 could represent a tumor promoter in HCC, an improved understanding of the action of DCLK1 is required. DCLK1 possesses two N-termini that are similar to doublecortin (DCX)-binding microtubules and regulate neural progenitor cell migration (37). The C-terminal domain contains a serine/threonine protein kinase. However, lacking definitive evidence that DCLK1 resembles a cyclic adenosine monophosphate (cAMP) dependent kinase, its structural homology to $\mathrm{Ca}^{2+} /$ calmodulin-dependent (CAM) kinase still warrants consideration that this protein may show stimulation of its activity by Ca-calmodulin $(38,39)$. DCLK1 and DCX are members of the DCX family (37). DCX expressed in newly differentiated neurons (40) has also been implicated in regulating neuronal migration and axon growth $(41,42)$. A previous mouse study revealed that DCLK1 and DCX exhibit a compensatory function in the formation of axonal projections across the midline, and migration of cortical neurons (39). Another study suggested that phosphorylated DCX in vitro and in vivo was associated with tumor invasion and progression (43). However, the underlying mechanism remains to be fully understood.

The present study suggested that DCLK1 expression increased the aggressiveness of $\mathrm{HCC}$, which requires further study. One previous study revealed that DCLK1-expressing tumor cells with stemness properties were associated with tumorigenesis and metastasis, as regulated by specific miRNA pathways in HCC (31). miRNA, a type of non-coding RNA, functions primarily by binding to the $3^{\prime}$ untranslated region of a target mRNA. miRNA serves important functions in numerous life processes, including embryogenesis, stem cell differentiation, tumorigenesis and tumor progression $(44,45)$. In HCC tumors, DCLK1-specific small interfering (si)RNA resulted in tumor growth arrest, downregulation of DCLK1 and increased expression of multiple tumor suppressor miRNAs, including miR-200, miR-143/145 and miRNA let-7a (31).

The miR-200 family is a key regulator of the epithelial-mesenchymal transition (EMT). EMT, the phenotypic conversion of epithelial cells to mesenchymal cells (46), is a highly conserved process that is essential in cancer initiation, invasion and metastasis (47). Increasing miR-200 expression resulted in decreased expression of EMT-inducing transcription factors, including snail family transcriptional repressor (SNAI)1, SNAI2, zinc finger E-box binding homeobox (ZEB)1, ZEB2, twist family bHLH transcription factor 1 and forkhead box $\mathrm{C} 2$, and increased expression of EMT-inducing transcription factor epithelial cadherin $(20,31)$. These previous studies suggested that DCLK1 serves a crucial function in promoting EMT and invasion by regulating miR-200. miR-143/145 was revealed to possess tumor suppressor properties, repressing the expression of POU class 5 homeobox 1 , SRY-box 2 and Kruppel like factor 4, and thereby repressing pluripotency, controlling differentiation and inhibiting metastasis (48). The downregulation of miRNA let-7a serves an important function in liver and pancreatic tumor pathogenesis. MYC proto-oncogene (MYC), targeted by miRNA let-7a, revealed decreased expression following knockdown 


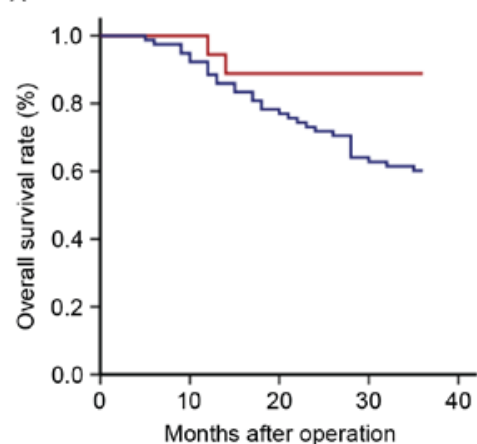

C

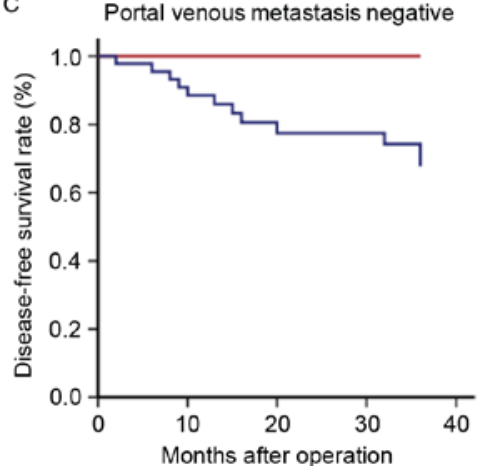

E
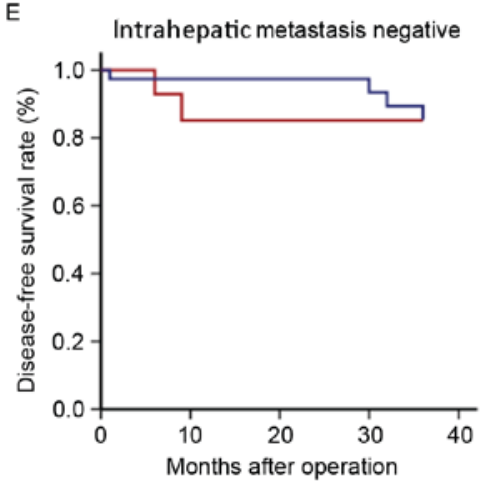

G

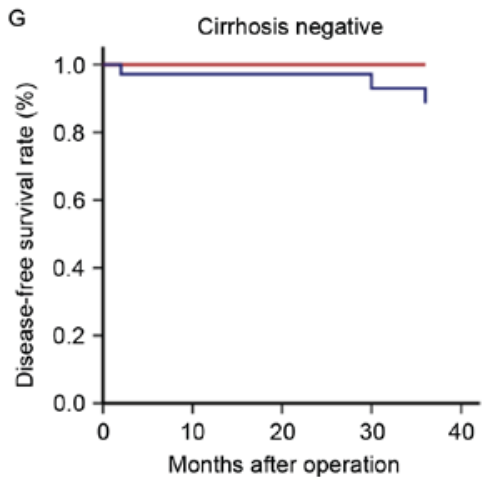

B

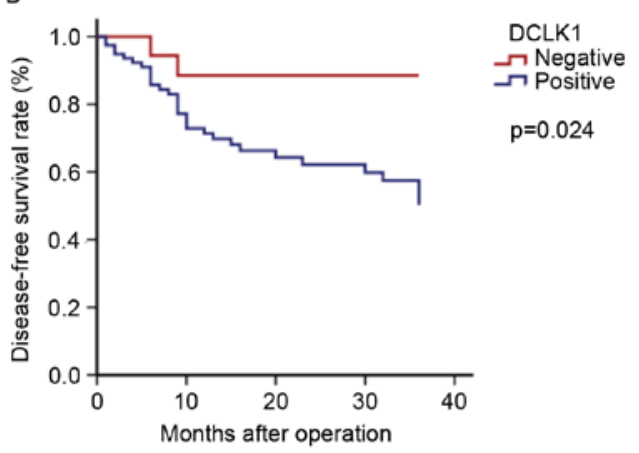

D Portal venous metastasis positive

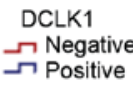

$\Omega$ Negative

$p=0.105$

DCLK1

$\rightarrow$ Negative

$p=0.627$

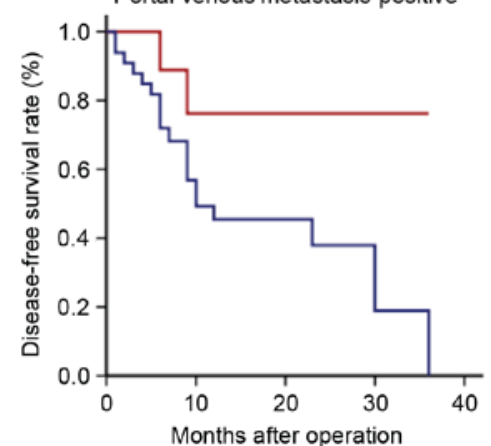

DCLK1

$\neg$ Negative

$p=0.020$

F Intrahepatic metastasis positive

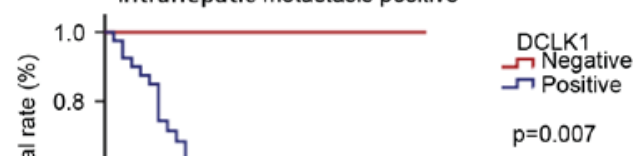

$p=0.007$

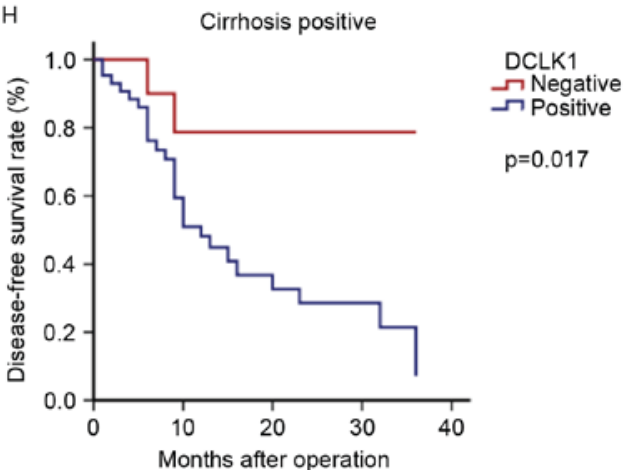

DCLK1
$\neg$ Negative
$\sim$ Positive

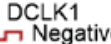

Negative

$\mathrm{p}=0.352$

$\mathrm{H}$

Figure 3. Kaplan-Meier curves of DFS and OS for patients with HCC according to DCLK1 expression. (A) OS and (B) DFS in HCC according to positive/negative DCLK1 expression. DFS in (C) portal venous metastasis-negative and (D) -positive HCC according to positive/negative DCLK1 expression. DFS in (E) intrahepatic metastasis-negative and (F) -positive HCCaccording to positive/negative DCLK1 expression. DFS in (G) cirrhosis-negative and (H) -positive HCC according to positive/negative DCLK1 expression. DFS, disease-free survival; OS, overall survival; HCC, hepatocellular carcinoma; DCLK1, doublecortin-like kinase 1.

of DCLK1 in HCC cells (31). Furthermore, a similar mechanism was detected in pancreatic and colorectal cancer $(20,23)$. The factors associated with EMT, pluripotency and cancer stemness serve a multifaceted function in tumorigenesis and metastasis in HCC, which are controlled by DCLK1 (31).
Histopathological assessment of tissues from chronic liver diseases, in vitro experiments and murine models have supported the existence of CSCs in HCC $(15,49)$. A previous study revealed that hepatitis $\mathrm{C}$ virus replication was positively associated with DCLK1 expression (25). By contrast, 
siRNA knockdown of DCLK1 diminished hepatitis C virus replication and lowered the expression of EMT-promoting factors $(21,25,26)$. Furthermore, DCLK1 served a crucial function in the development of cirrhosis and $\mathrm{HCC}$ following sustained hepatitis $C$ virus infection (50). In FCA4 cell lines (heterogeneous hepatoma cells with persistent replication of hepatitis C virus RNAs), DCLK1 activated the inflammatory cascade, as detected by S100 calcium binding protein A9 and nuclear factor $\mathrm{\kappa B}$, and then promoted tumor proliferation, cell mortality, invasion and EMT via MYC pathways (50). Collectively, inflammation and neoplastic transformation are regulated by a feed-forward-like loop of the DCLK1 signaling pathway during chronic liver diseases (50). HCC associated with infection with HBV has become one of the fastest-rising causes of cancer-associated mortality in China $(2,51)$. Given the importance of DCLK1 inflammatory and oncogenic functions in virus-induced chronic diseases $(25,31,50)$. the present study assessed the association between DCLK1 expression and hepatitis B virus and cirrhosis levels. The present study observed that DCLK1 expression was a negative survival predictor in cirrhosis subgroups. However, no association was observed between DCLK1 expression and hepatitis B virus status, this may be associated with the small number of specimens. Further study is required to assess the association between DCLK1 expression and hepatitis B virus in patients with HCC.

The present study revealed that DCLK1 expression was an independent prognostic parameter for DFS, but not OS, in patients with HCC. One of the main reasons for this was a lack of long-term follow-up in the present study. At a median follow-up of 30 months, 50 patients developed recurrence, 30 of who succumbed. The present study would have been improved with extended follow-up, an increased number of samples and consecutive survival data. Furthermore, in stratified survival analysis, the present study observed that DCLK1 expression predicted early tumor recurrence and poorer DFS rates with regard to portal venous metastasis, intrahepatic metastasis, and cirrhosis patient subgroups, which was consistent with the multi-functional role of DCLK1 in HCC. These novel data revealed the potential of DCLK1-targeted therapy. DCLK1 may serve a function in multiple types of solid tumor. In a previous study, siRNA-mediated blockade of DCLK1 resulted in colorectal tumor xenograft growth arrest in nude mice and a corresponding decrease in luciferase activity (23). Furthermore, another study demonstrated that the ablation of DCLK1-expressing cells resulted in a decrease in the number of intestinal polyps in APC (Min)/+ mice (9). In addition, the stable knockdown of DCLK1 resulted in the regression of liver metastasis lesions in pancreatic cancer cells (52). Taken together, these data suggested a function for DCLK1 in regulating tumor growth and indicate that small molecular inhibitors of DCLK1 may prove useful as antitumor drugs. Furthermore, DCLK1 expression may be used to predict early tumor recurrence and poor clinical outcome across the three subgroups of patients with HCC described in the present study. However, the results of the present study require confirmation in larger patient cohorts.

To conclude, the present study together with previous study results have underscored the importance of DCLK1 expression in HCC. Progress in HCC treatments has stagnated over recent decades, despite clinical trials of novel therapies. Aggressive surgical therapies and early interventions following surgery could be used to control local invasion and early recurrence. The present study revealed that DCLK1 expression was associated with a poorer prognostic outcome in patients with HCC, and in the portal venous metastasis, intrahepatic metastasis and cirrhosis patient subgroups. Therefore, DCLK1 may represent a promising therapeutic target for HCC.

\section{Acknowledgements}

The authors would like to thank Dr Bing Li and Dr Jing Yuan (Chinese People's Liberation Army General Hospital,Pathology Department.) for their technical assistance. The present study was supported by the Technology Nova Plan of Beijing City (grant no. xx2013107).

\section{References}

1. Torre LA, Bray F, Siegel RL, Ferlay J, Lortet-Tieulent J and Jemal A: Global cancer statistics 2012. CA Cancer J Clin 65: 87-108, 2015

2. El-Serag HB: Hepatocellular carcinoma. N Eng1 J Med 365: 1118-1127, 2011.

3. Sarasin FP, Giostra E and Hadengue A: Cost-effectiveness of screening for detection of small hepatocellular carcinoma in western patients with Child-Pugh class A cirrhosis. Am J Med 101: 422-434, 1996.

4. Cervello M, McCubrey JA, Cusimano A, Lampiasi N, Azzolina A and Montalto G: Targeted therapy for hepatocellular carcinoma: Novel agents on the horizon. Oncotarget 3: 236-260, 2012.

5. Lin PT, Gleeson JG, Corbo JC, Flanagan L and Walsh CA: DCAMKL1 encodes a protein kinase with homology to doublecortin that regulates microtubule polymerization. J Neurosci 20: 9152-9161, 2000.

6. Ohmae S, Takemoto-Kimura S,Okamura M,Adachi-MorishimaA, Nonaka M, Fuse T, Kida S, Tanji M, Furuyashiki T, Arakawa $\mathrm{Y}$, et al: Molecular identification and characterization of a family of kinases with homology to $\mathrm{Ca} 2+/$ calmodulin-dependent protein kinases I/IV. J Biol Chem 281: 20427-20439, 2006.

7. Giannakis M, Stappenbeck TS, Mills JC, Leip DG, Lovett M, Clifton SW, Ippolito JE, Glasscock JI, Arumugam M, Brent MR and Gordon JI: Molecular properties of adult mouse gastric and intestinal epithelial progenitors in their niches. J Biol Chem 281: 11292-11300, 2006.

8. May R, Riehl TE, Hunt C, Sureban SM, Anant S and Houchen CW: Identification of a novel putative gastrointestinal stem cell and adenoma stem cell marker, doublecortin and CaM kinase-like-1, following radiation injury and in adenomatous polyposis coli/multiple intestinal neoplasia mice. Stem Cells 26: 630-637, 2008.

9. Nakanishi Y, Seno H, Fukuoka A, Ueo T, Yamaga Y, Maruno T, Nakanishi N, Kanda K, Komekado H, Kawada M, et al: Dclk1 distinguishes between tumor and normal stem cells in the intestine. Nat Genet 45: 98-103, 2013.

10. Westphalen CB, Asfaha S, Hayakawa Y, Takemoto Y, Lukin DJ, Nuber AH, Brandtner A, Setlik W, Remotti H, Muley A, et al: Long-lived intestinal tuft cells serve as colon cancer-initiating cells. J Clin Invest 124: 1283-1295, 2014.

11. Westphalen CB, Quante M, Worthley D, Asfaha S, Remotti H, Olive KP and Wang TC: Dclk1 labels quiescent pancreatic progenitor and cancer initiating cells. Cancer Res 72 (Suppl): Abstract 5220, 2012.

12. Bonnet D and Dick JE: Human acute myeloid leukemia is organized as a hierarchy that originates from a primitive hematopoietic cell. Nat Med 3: 730-737, 1997.

13. Al-Hajj M, Wicha MS, Benito-Hernandez A, Morrison SJ and Clarke MF: Prospective identification of tumorigenic breast cancer cells. Proc Natl Acad Sci USA 100: 3983-3988, 2003.

14. Li C, Heidt DG, Dalerba P, Burant CF, Zhang L, Adsy V, Wicha M, Clarke MF and Simeone DM: Identification of pancreatic cancer stem cells. Cancer Res 67: 1030-1037, 2007. 
15. Mishra L, Banker T, Murray J, Byers S, Thenappan A, He AR, Shetty K, Johnson L and Reddy EP: Liver stem cells and hepatocellular carcinoma. Hepatology 49: 318-329, 2009.

16. Lobo NA, Shimono Y, Qian D and Clarke MF: The biology of cancer stem cells. Annu Rev Cell Dev Biol 23: 675-699, 2007.

17. Singh SK, Hawkins C, Clarke ID, Squire JA, Bayani J, Hide T, Henkelman RM, Cusimano MD and Dirks PB: Identification of human brain tumor initiating cells. Nature 432: 396-401, 2004.

18. Diehn M and Clarke MF: Cancer stem cells and radiotherapy: New insights into tumor radioresistance. J Natl Cancer Inst 98: 1755-1757, 2006.

19. Tang C, Ang BT and Pervaiz S: Cancer stem cell: Target for anti-cancer therapy. FASEB J 21: 3777-3785, 2007.

20. Sureban SM, May R, Lightfoot SA, Hoskins AB, Lerner M, Brackett DJ, Postier RG, Ramanujam R, Mohammed A Rao CV, et al: DCAMKL-1 regulates epithelial-mesenchymal transition in human pancreatic cells through a miR-200a-dependent mechanism. Cancer Res 71: 2328-2338, 2011.

21. Sureban SM, May R, Mondalek FG, Qu D, Ponnurangam S, Pantazis P, Anant S, Ramanujam RP and Houchen CW: Nanoparticle-based delivery of siDCAMKL-1 increases microRNA-144 and inhibits colorectal cancer tumor growth via a Notch-1 dependent mechanism. J Nanobiotechnology 9: 40, 2011.

22. Sureban SM, May R, Qu D, Weygant N, Chandrakesan P, Ali N, Lightfoot SA, Pantazis P, Rao CV, Postier RG and Houchen CW: DCLK1 regulates pluripotency and angiogenic factors via microRNA-dependent mechanisms in pancreatic cancer. PLoS One 8: e73940, 2013.

23. Sureban SM, May R, Ramalingam S, Subramaniam D, Natarajan G, Anant S and Houchen CW: Selective blockade of DCAMKL-1 results in tumor growth arrest by a Let-7a MicroRNA-dependent mechanism. Gastroenterology 137: 649-659.e1-2, 2009.

24. Sureban SM, May R, Weygant N, Qu D, Chandrakesan P, Bannerman-Menson E, Ali N, Pantazis P, Westphalen CB Wang TC and Houchen CW: XMD8-92 inhibits pancreatic tumor xenograft growth via a DCLK1-dependent mechanism. Cancer Lett 351: 151-161, 2014.

25. Ali N, Allam H, May R, Sureban SM, Bronze MS, Bader T, Umar S, Anant S and Houchen CW: Hepatitis C virus-induced cancer stem cell-like signatures in cell culture and murine tumor xenografts. J Virol 85: 12292-12303, 2011.

26. May R, Sureban SM, Hoang N, Riehl TE, Lightfoot SA RamanujamR,WycheJH,AnantS and Houchen CW: Doublecortin and $\mathrm{CaM}$ kinase-like-1 and leucine-rich-repeat-containing G-protein-coupled receptor mark quiescent and cycling intestinal stem cells, respectively. Stem Cells 27: 2571-2579, 2009.

27. Gagliardi G, Goswami M, Passera R and Bellows CF: DCLK1 immunoreactivity in colorectal neoplasia. Clin Exp Gastroenterol 5: 35-42, 2012.

28. Saqui-Salces M, Keeley TM, Grosse AS, Qiao XT, EL-Zaatari M, Gumucio DL, Samuelson LC and Merchant JL: Gastric tuft cells express DCLK1 and are expanded in hyperplasia. Histochem Cell Biol 136: 191-204, 2011.

29. Ikezono Y, Koga H, Abe M, Akiba J, Kawahara A, Yoshida T, Nakamura T, Iwamoto H, Yano H, Kage M, et al: High expression of the putative cancer stem cell marker, DCLK1, in rectal neuroendocrine tumors. Oncol Lett 10: 2015-2020, 2015.

30. Hao XP, Willis JE, Pretlow TG, Rao JS, MacLennan GT, Talbot IC and Pretlow TP: Loss of fragile histidine triad expression in colorectal carcinomas and premalignant lesions. Cancer Res 60: 18-21, 2000.

31. Sureban SM, Madhoun MF, May R, Qu D, Ali N, Fazili J, Weygant N, Chandrakesan P, Ding K, Lightfoot SA and Houchen CW: Plasma DCLK1 is a marker of hepatocellular carcinoma (HCC): Targeting DCLK1 prevents HCC tumor xenograft growth via a microRNA-dependent mechanism. Oncotarget 6: 37200-37215, 2015.

32. Fattovivh G, Stroffoloni T, Zagni I and Donato F: Hepatocellular carcinoma in cirrhosis: Incidence and risk factors Gastroenterology 127 (5 Suppl 1): S35-S50, 2004.

33. Torzilli G, Belghiti J, Kokudo N, Takayama T, Capussotti L, Nuzzo G, Vauthey JN, Choti MA, De Santibanes E, Donadon M, et al: A snapshot of the effective indications and results of surgery for hepatocellular carcinoma in tertiary referra centers: Is it adherent to the EASL/AASLD recommendations? An observational study of the HCC East-West study group. Ann Sugr 257: 929-937, 2013.
34. Fan ST, Poon RT, Yeung C, Lam CM, Lo CM, Yuen WK, Ng KK, Liu CL and Chan SC: Outcome after partial hepatectomy for hepatocellular cancer within the Milan criteria. Br J Surg 98: 1292-1300, 2011

35. O'Connell MR, Sarkar S, Luthra GK, Okugawa Y, Toiyama Y, Gajjar AH, Qiu S, Goel A and Singh P: Epigenetic changes and alternate promoter usage by human colon cancers for expressing DCLK1-isoforms: Clinical Implications. Sci Rep 5: 14983, 2015.

36. Meng QB, Yu JC, Kang WM, Ma ZQ, Zhou WX, Li J, Zhou L, Cao ZJ and Tian SB: Expression of doublecortin-like kinase 1 in human gastric cancer and its correlation with prognosis. Zhongguo Yi Xue Ke Xue Yuan Xue Bao 35: 639-644, 2013 (In Chinese).

37. Reiner O, Coquelle FM, Peter B, Levy T, Kaplan A, Sapir T, Orr I, Barkai N, Eichele G and Bergmann S: The evolving doublecortin (DCX) superfamily. BMC Genomics 7: 188, 2006.

38. Lin PT, Gleeson JG, Corbo JC, Flanagan L and Walsh CA: DCAMKL1 encodes a protein kinase with homology to doublecortin that regulates microtubule polymerization. J Neurosci 20 9152-9161 2000.

39. Koizumi H, Tanaka T and Gleeson JG: Doublecortin-like kinase functions with doublecortin to mediate fiber tract decussation and neuronal migration. Neuron 49: 55-66, 2006.

40. Gleeson JG, Minnerath SR, Fox JW, Allen KM, Luo RF, Hong SE, Berg MJ, Kuzniecky R, Reitnauer PJ, Borgatti R, et al: Characterization of mutations in the gene doublecortin in patients with double cortex syndrome. Ann Neurol 45: 146-153, 1999.

41. Gleeson JG, Lin PT, Flanagan LA and Walsh CA: Doublecortin is a microtubule-associated protein and is expressed widely by migrating neurons. Neuron 23: 257-271, 1999.

42. Schaar BT, Kinoshita K and McConnell SK: Doublecortin microtubule affinity is regulated by a balance of kinase and phosphatase activity at the leading edge of migrating neurons. Neuron 41: 203-213, 2004.

43. Clark EA, Golub TR, Lander ES and Hynes RO: Genomic analysis of metastasis reveals an essential role for RhoC. Nature 406: 532-535, 2000

44. McManus MT: MicroRNAs and cancer. Semin Cancer Biol 13: 253-258, 2003

45. Takamizawa J, Konishi $\mathrm{H}$, Yanagisawa $\mathrm{K}$, Tomida S, Osada $\mathrm{H}$, Endoh H, Harano T, Yatabe Y, Nagino M, Nimura Y, et al: Reduced expression of the let-7 microRNAs in human lung cancers in association with shortened postoperative survival. Cancer Res 64: 3753-3756, 2004

46. Turley EA, Veiseh M, Radisky DC and Bissell MJ: Mechanisms of disease: Epithelial-mesenchymal transition-does cellular plasticity fuel neoplastic progression? Nat Clin Pract Oncol 5: 280-290, 2008

47. Diehn M and Clarke MF: Cancer stem cells and radiotherapy: New insights into tumor radioresistance. J Natl Cancer Inst 98: $1755-1757,2006$.

48. Xu N, Papagiannakopoulos T, Pan G, Thomson JA and Kosik KS MicroRNA-145 regulates OCT4, SOX2, and KLF4 and represses pluripotency in human embryonic stem cells. Cell 137: 647-658, 2009.

49. Yamashita $\mathrm{T}$ and Wang XW: Cancer stem cells in the development of liver cancer. J Clin Invest 123: 1911-1918, 2013.

50. Ali N, Chandrakesan P, Nguyen CB, Husain S, Gillaspy AF, Huycke M, Berry WL, May R, Qu D, Weygant N, et al: Inflammatory and oncogenic roles of a tumor stem cell marker doublecortin-like kinase (DCLK1) in virus-induced chronic liver diseases. Oncotaarget 6: 20327-20344, 2015.

51. Lata J: Chronic liver diseases as liver tumor precursors. Dig Dis 28: $596-599,2010$

52. Ito H, Tanaka S, Akiyama $\mathrm{Y}$, Shimada S, Adikrisna R, Matsumura S, Aihara A, Mitsunori Y, Ban D, Ochiai T, et al: Dominant expression of DCLK1 in human pancreatic cancer stem cells accelerates tumor invasion and metastasis. PLoS One 11: e0146564, 2016 